\title{
TANDEM-X MISSION STATUS, PRODUCTS AND PERSPECTIVES
}

\author{
J. Böer ${ }^{1}$ *, C. Wecklich ${ }^{1}$, M. Bachmann ${ }^{1}$, S. Buckreuss ${ }^{1}$, P. Rizzoli ${ }^{1}$, M. Zink ${ }^{1}$ \\ ${ }^{1}$ Microwaves and Radar Institute, German Aerospace Center (DLR), Germany - johannes.boeer@dlr.de
}

KEY WORDS: TanDEM-X, Digital Elevation Model (DEM), Interferometry, Remote Sensing, Synthetic Aperture Radar (SAR)

\begin{abstract}
:
TanDEM-X is an innovative single-pass interferometric radar mission, which is comprised of two formation flying satellites. The TerraSAR-X (TSX) satellite was launched on June 15th 2007, and its almost identically constructed twin satellite TanDEM-X (TDX) was launched on 21st of June 2010. Together they supply high-quality radar data in order to serve two main mission goals: Scientific observation of the Earth and provision of remote sensing data for the commercial market (TerraSAR-X mission), and the generation of a global digital elevation model (DEM) of the Earth's surface (TanDEM-X mission). Between December 2010 and early 2015, radar data of all land surfaces has been acquired and as of September 2016 the final TanDEM-X DEM dataset has been available. This paper provides a final quality assessment of the TanDEM-X global DEM products with respect to the relative and absolute height accuracy and data coverage both at the global and geocell level. In addition, an overview on current mission status is given and new DEM products, which are currently in the scope of the TanDEM-X mission, are described.
\end{abstract}

\section{SPACECRAFT STATUS}

The satellites TSX and TDX have been designed for an in-orbit lifetime of 5.5 years. By now, they have completed eleven and eight years in orbit, respectively. Both spacecraft are still fully functional and SAR operations do not suffer from any restriction due to on-board hardware degradations. A few aspects shall be discussed here in more detail.

The state of depletion of consumables gives reason to expect at least three more years of satellite operations. Currently the propellant filling level of TSX is about $46 \%$ and $43 \%$ for TDX. The consumption of propellant (Hydrazine) depends on the number of manoeuvers and the external conditions like aerodynamic drag, solar activity, tidal forces and space debris avoidance manoeuvers. Another component that has to be considered is the adjustment of the formation between TSX and TDX for bistatic operations, which consumes a large portion of propellant on the TDX satellite. As the filling level of cold gas, the additional propellant that is used for these fine formation adjustments, is now at about $10 \%$, a strategy called "distributed formation flying" has been developed and is operationally applied since February 2016. Since then both satellites contribute to the formation maintenance, which means that small orbit raising manoeuvers are scheduled for TSX on a daily basis, depending on the current formation setting. Analyses show that the TerraSAR-X orbit control accuracy is not negatively influenced by the new concept.

System health, including the ground segment components, is constantly being monitored, as the quality of the SAR products strongly depends on the absolute calibration and on the stability of the whole system. The monitoring includes health checks of the SAR antenna's transmitting and receiving (T/R) modules, regular acquisitions over point and distributed targets, UltraStable Oscillator frequency measurements, interferometric baseline monitoring and a statistical evaluation of SAR signal properties and calibration parameters that reflect the performance of the overall interferometric SAR system (Bojarski et al. 2018).
Besides the solar panels, the battery of each satellite as part of the power subsystem is another crucial element for the functionality of the system. It considerably contributes to the life-time of the satellites and constitutes a limiting factor to the acquisition planning strategy. Ageing effects that have to be considered here are a gradual reduction of available battery capacity and internal electrical effects. Regular monitoring of the batteries of both satellites shows them to be in excellent health with less degradation than originally predicted. Nonetheless measures have been operationally implemented in order to reduce the stress on the batteries. This includes a limitation of maximum allowed datatake length during the yearly polar Eclipse season, when the satellites' orbits are partly shadowed from the Sun, but also by preserving a minimum temporal separation in the succession of longer datatakes during that time. This poses some restrictions on the TanDEM-X mission, which favours long acquisitions for the benefit of a homogeneous DEM performance.

\section{MISSION STATUS}

Since 2010, the two satellites TerraSAR-X and TanDEM-X have been flying as a large single-pass bistatic SAR interferometer in a close helix formation. The distance between the two satellites varies from $120 \mathrm{~m}$ to several hundred of meters (Krieger et al. 2007). The acquisition of the global TanDEM-X DEM took place until 2014. During this time, at least two global coverages (including Antarctica) were performed. Over mountainous terrain two additional coverages were acquired from an opposite viewing direction in order to resolve shadow and layover effects. Until 2016, the data was processed and mosaicked together to generate the final global DEM of all landmasses.

Since 2014, dedicated phases concentrating on formations for scientific purposes were flown (Hajnsek et al. 2014). Examples for the applications served with data from these scientific phases are:

\footnotetext{
* Corresponding author
} 
- Agricultural monitoring of the vegetation growing cycle with very large baseline up to $3.6 \mathrm{~km}$

- $\quad$ Forest monitoring utilizing the full-polarimetric mode of TerraSAR-X/TanDEM-X

- Monitoring of glaciers at high latitudes by flying in a constellation where the satellites are separated in flight direction by about $76 \mathrm{~km}$

An additional phase concentrated on the acquisition and demonstration of DEMs with an increased horizontal and vertical resolution (called High-Resolution DEMs).

\section{GLOBAL DEM PRODUCT}

Digital Elevation Models (DEMs) are raster-based digital datasets that are of fundamental importance for a wide range of scientific and commercial applications. Within the $\pm 60^{\circ}$ latitude band, up to now, data from the Shuttle Radar Topography Mission (SRTM) had been the primary source of elevation information.

Primary mission goal of TanDEM-X was the generation of a world-wide, consistent, current and high-precision DEM, with a spatial resolution of 0.4 arcseconds ( $12 \mathrm{~m}$ at the equator) and according to the height accuracy and data coverage shown in Table 1. DEM data acquisition is based on SAR interferometry, which evaluates the phase difference between two coherent radar signals acquired from slightly different spatial and/or temporal positions. The height of the scatterer is then inferred from this range difference by geometric triangulation. As the TanDEM-X radar operates in the X-band, the resulting height represents the reflecting surface of the radar backscatter, or more specifically the phase center of the reflection.

The TanDEM-X global DEM acquisition started in December 2010 and the first global coverage (except Antarctica) was completed in January 2012. By the end of 2014, the Earth's entire land mass had been mapped at least twice (four times in the case of difficult terrain) with varying baselines. Antarctica has also been mapped twice during local winter conditions. The TanDEM-X mapping strategy has been optimized throughout the mission, in order to optimize the final performance in terms of relative height accuracy.

\begin{tabular}{|l|c|c|}
\hline Parameter & Accuracy & Requirement \\
\hline $\begin{array}{l}\text { Absolute Height } \\
\text { Accuracy }\end{array}$ & $\begin{array}{c}90 \% \text { linear error }- \\
\text { globally }\end{array}$ & $\leq 10$ meters \\
\hline $\begin{array}{l}\text { Relative Height } \\
\text { Accuracy }\end{array}$ & $\begin{array}{c}90 \% \text { linear point-to- } \\
\text { point error in } 1^{\circ} \times 1^{\circ} \\
\text { geocell }\end{array}$ & $\begin{array}{c}\leq 2 \text { meters } \\
\text { (slope } \leq 20 \%)\end{array}$ \\
\cline { 2 - 3 } & $\begin{array}{c}\leq 4 \text { meters } \\
\text { (slope }>20 \%)\end{array}$ \\
\hline Data Coverage & \multicolumn{2}{|c|}{$97 \%$ of all global land mass } \\
\hline
\end{tabular}

Table 1. TanDEM-X performance requirements

Once all of the input data for a given geocell $\left(1^{\circ} \mathrm{x} 1^{\circ}\right.$ in latitude/longitude, ca. $110 \mathrm{~km}$ by $110 \mathrm{~km}$ at the equator) have been processed, remaining tilts and offsets have been calibrated out against a subset of external ICESat data and differences between overlapping TanDEM-X acquisitions harmonized. In total more than 500,000 so-called Raw DEMs have been generated and evaluated in a fully automated process employing multi-baseline interferometric techniques. Lastly, the mosaicking processor combined all elevation data and produced almost 20,000 final DEM tiles with the targeted $12 \mathrm{~m}$ posting.

\subsection{Relative Height Accuracy}

The relative height accuracy, which quantifies the random noise contribution within the final DEM, is estimated from the interferometric coherence. This information can also be found in the TanDEM-X DEM products. For this, the products contain an additional layer called Height Error Map (HEM) (Wessel, 2016). It has been separately evaluated for both flat (predominant slope lower than 20\%) and steep terrain (predominant slope higher than 20\%). The mission specification at $90 \%$ confidence level, which is $2 \mathrm{~m}$ and $4 \mathrm{~m}$ for flat and steep terrain, respectively, is met on a global scale for $97.76 \%$ of all geocells not disclaimed due to volume decorrelation effects. Moreover, more than $50 \%$ of all DEM geocells and about $70 \%$ of them show a relative height accuracy at $90 \%$ confidence level better than $1 \mathrm{~m}$ for flat terrain and better than $2 \mathrm{~m}$ for steep terrain, respectively. A dedicated analysis shows that, at a global scale, the relative height accuracy at $90 \%$ confidence level for vegetated areas remains under $2 \mathrm{~m}$ for both flat and steep terrain.

\subsection{Absolute Height Accuracy}

The absolute vertical height accuracy is defined as the uncertainty in the height of a point with respect to the WGS84 ellipsoid caused by low-varying and uncorrected systematic errors. The accuracy has been globally validated using the ICESat points that have not already been utilized in the calibration process, thus making them disjunct from each other.

When evaluating the absolute height accuracy on a global scale, only the first 1,000 points with the lowest height variation between DEM pixels within an ICESat footprint are considered. This approach aims to assure that the majority of geocells are validated with a comparable number of validation points. With this approach mainly flat regions are considered for the comparison, since they are characterized by the lowest spatial variance. However the validity of the proposed method is not compromised, as the main error sources are the remaining tilts and low-varying trends, which affect the entire geocell. In the end, geocells with fewer validation points (e.g. coastal regions) are evaluated with similar weight as geocells with more copious validation points.

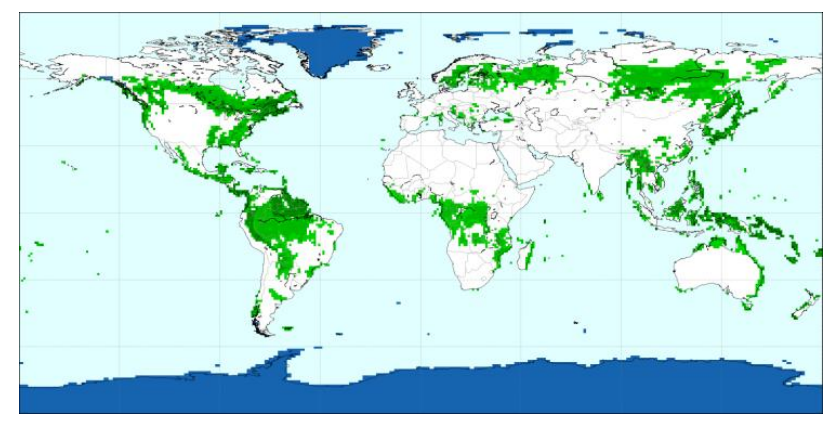

Figure 1: Forest (green) and Ice (Blue) assignment for the Absolute Height Accuracy Evaluation

When evaluating the absolute height accuracy, all tiles are assigned to the following categories which are derived from the European Space Agency's (ESA) Climate Change Initiative Land Cover classification map (CCI, 2014) and PALSAR forest/non-forest map (Shimada et al. 2014): Forest, where the forest coverage is greater than $60 \%$, Ice, where the ice coverage is greater than $60 \%$ and includes all of Antarctica, and Generic, 
which do not contain forest nor ice tiles. This separation is shown in Figure 1. It should be mentioned that the final three rows of DEM tiles, namely latitudes from -90 to -88 degrees, over Antarctica have no ICESat data points for validation as the ICESat system did not cover this region.

For the complete global performance, which includes both ice and forest lands, the system specification of an absolute global height accuracy of at most 10 meters with a $90 \%$ linear error is met and far exceeded with an overall accuracy of 3.49 meters. The results are shown in Table 2. It should be noted that the height differences seen in the ice and forest regions are not errors, rather they are characteristics of a phase center measuring radar system. When one evaluates the statistics on a tile-by-tile basis, out of 19,389 analyzed geocells, only 328 tiles or $1.69 \%$ have an absolute height accuracy greater than $10 \mathrm{~m}$. The vast majority of the geocells, over 10,954 or $56 \%$, have an absolute height accuracy of less than $2 \mathrm{~m}$.

\begin{tabular}{|l|c|c|c|c|}
\hline Statistics & $\begin{array}{c}\text { Generic } \\
\text { Land }\end{array}$ & $\begin{array}{c}\text { Ice } \\
\text { Only }\end{array}$ & $\begin{array}{c}\text { Forest } \\
\text { Only }\end{array}$ & $\begin{array}{c}\text { All } \\
\text { geocells }\end{array}$ \\
\hline $\begin{array}{l}\text { Number of DEM } \\
\text { Tiles }\end{array}$ & 12,257 & 3,019 & 4,113 & 19,389 \\
\hline $\begin{array}{l}\text { Landmass } \\
\text { (millions km })^{2}\end{array}$ & 97 & 14 & 33 & 144 \\
\hline $\begin{array}{l}\text { Number of Val. } \\
\text { Points (millions) }\end{array}$ & 10 & 2 & 3 & 15 \\
\hline $\begin{array}{l}\text { Mean Height } \\
\text { Deviation of Val. } \\
\text { Points (m) }\end{array}$ & 0.0448 & -2.8329 & 0.5687 & -0.3707 \\
\hline $\begin{array}{l}\text { Absolute Height } \\
\text { Accuracy of 10 m } \\
\text { (linear error) }\end{array}$ & $99.84 \%$ & $98.42 \%$ & $99.17 \%$ & $99.48 \%$ \\
\hline $\begin{array}{l}\text { Absolute Height } \\
\text { Accuracy with } \\
\text { 90\% Linear Error } \\
\text { (m) }\end{array}$ & 0.877 & 6.372 & 2.33 & 3.494 \\
\hline
\end{tabular}

Table 2. Summary of final Absolute Height Accuracy

The comparison of the different categories in the table shows that geocells dominated by ice or forest, which are affected by volume decorrelation, have reduced absolute height accuracy.
On the other hand, when considering only geocells dominated by generic land surface, which is the majority of geocells, an accuracy of less than one meter is achieved.

\subsection{Data Coverage}

Voids, i.e. invalid pixels, in DEM data arise when a pixel's height value cannot be determined during processing and can occur in a SAR system for various reasons, including phase unwrapping anomalies, low return signal power, or shadow/layover effects. The TanDEM-X final DEM is specified to a data coverage requirement of $97 \%$ of all global land masses and therefore the global data set can have up to $3 \%$ invalid data points (voids) over land areas.

Out of the total 19,389 geocells in the TanDEM-X dataset, voids over land account for only $0.11 \%$ of the entire data set. In other words the data coverage is currently better than $99.89 \%$. Over $67 \%$ of the geocells do not contain any invalid data pixels.

\section{UPDATE OF THE GLOBAL DEM}

The original TanDEM-X DEM product was successfully completed and delivered to the commercial partner Airbus D\&S, and great scientific interest was raised with the scientific release of the DEM data. However, a part of the data used for DEM generation is already more than seven years old. Hence, a lot of changes in the topography of the Earth took place during that time.

On the other hand, the satellites are still in good shape and there are sufficient consumables for several more years of operation left (Buckreuss et al. 2018). Thus, the mission decided to acquire a further global coverage in order to update the first global digital elevation model in form of a new and independent, self-contained product, that can be used to assess, on a global scale, temporal changes w.r.t. the original TanDEM$\mathrm{X}$ DEM product. For this purpose the Earth was separated in dedicated acquisition areas according to the dominant land classes and terrain types as shown in Figure 2. For each acquisition area certain acquisition constraints listed in Table 3 need to be observed.

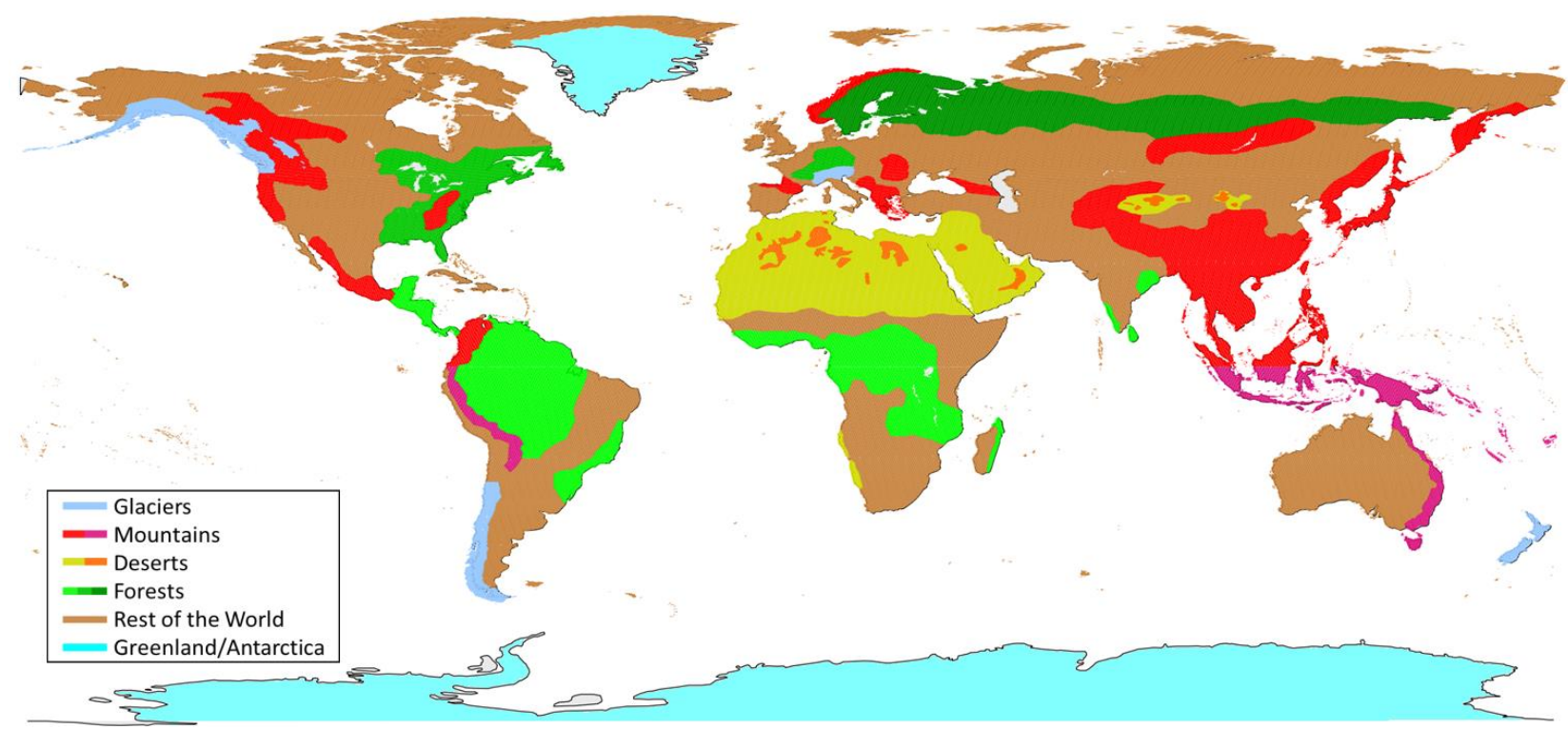

Figure 2. Acquisition areas for the TanDEM-X Change DEM 


\begin{tabular}{|c|c|c|c|}
\hline Region & $\begin{array}{l}\text { Cover- } \\
\text { ages }\end{array}$ & Season & $\begin{array}{l}\text { Height of } \\
\text { Ambiguity }\end{array}$ \\
\hline Glaciers & 2 & $\begin{array}{l}\text { Local } \\
\text { winter }\end{array}$ & $\begin{array}{l}55-75 \mathrm{~m}\left(1^{\mathrm{st}}\right) \\
45-53 \mathrm{~m}\left(2^{\mathrm{nd}}\right)\end{array}$ \\
\hline $\begin{array}{l}\text { Mountains } \\
\text { with Forest }\end{array}$ & 2 & $\begin{array}{l}\text { Local } \\
\text { summer }\end{array}$ & $\begin{array}{l}55-75 \mathrm{~m}\left(1^{\mathrm{st}}\right) \\
45-53 \mathrm{~m}\left(2^{\mathrm{nd}}\right) \\
\end{array}$ \\
\hline Deserts & 1 & $\begin{array}{l}\text { Year } \\
\text { round }\end{array}$ & $23-45 m$ \\
\hline $\begin{array}{l}\text { Deserts with } \\
\text { Mountains }\end{array}$ & 2 & $\begin{array}{l}\text { Year } \\
\text { round }\end{array}$ & $\begin{array}{l}55-75 \mathrm{~m}\left(1^{\mathrm{st}}\right) \\
45-55 \mathrm{~m}\left(2^{\mathrm{nd}}\right) \\
\end{array}$ \\
\hline $\begin{array}{l}\text { Tropical for- } \\
\text { est }\end{array}$ & 1 & $\begin{array}{l}\text { Year } \\
\text { round }\end{array}$ & $50-60 \mathrm{~m}$ \\
\hline $\begin{array}{l}\text { Temperate \& } \\
\text { boreal forest }\end{array}$ & 1 & $\begin{array}{l}\begin{array}{l}\text { Local } \\
\text { summer }\end{array} \\
\end{array}$ & $50-55 \mathrm{~m}$ \\
\hline $\begin{array}{l}\text { Permafrost } \\
\text { area }\end{array}$ & 1 & \begin{tabular}{|l} 
Local \\
winter
\end{tabular} & $35-45 m$ \\
\hline $\begin{array}{l}\text { Rest of the } \\
\text { world }\end{array}$ & 1 & $\begin{array}{l}\text { Year } \\
\text { round }\end{array}$ & $35-45 m$ \\
\hline
\end{tabular}

Table 3. Acquisition parameters for the Change DEM Product.

These constraints reflect the lessons learned from the processing of the TanDEM-X DEM, where a number of disadvantages of the used acquisition strategy had to be faced. Many of these disadvantages could be reverted by dedicated additional acquisitions. The following list shows some of these lessons learned:

- Data over glaciers or snow-rich mountains explicitly need to be acquired during local winter time, as melting ice or snow shows a very bad SNR performance during summer time.

- The baseline and the corresponding height of ambiguity (HoA) needs to be different for different land types and should be in a well-defined range:

- Glaciers, mountains or mountainous forests need be acquired with HoAs between $45 \mathrm{~m}$ and $90 \mathrm{~m}$

- Tropical forests can be acquired year-round but with HoAs larger than $50 \mathrm{~m}$.

- Sandy deserts need to be acquired with very steep incidence angles to overcome the low backscatter of sand and hence to increase the low signal-to-noise ratio.

In addition, several operational constraints had to be considered for the acquisition planning. As previously mentioned, the length of individual datatakes shall be limited in order to account for the age of the batteries. Furthermore, a reduction in the number of used ground stations significantly reduced the amount of data that can be acquired.

With the input of the desired acquisition areas and planning constraints like the on-board resources, the maximum and average duration of acquisitions, the desired interferometric baselines and the preferred seasons the planning process was started. An acquisition timeline was derived using the TanDEM-X Acquisition Planner (Ortega-Miguez et al. 2012), which is the operational tool for the planning of all TanDEM-X acquisitions. The process delivered a feasible acquisition timeline in form of data takes and the corresponding acquisition parameters. Data acquisition is already being carried out and shall be completed within a well-defined time span (September 2017 until late 2019).

The Change DEM generation process benefits from improvements in the acquisition planning and the data processing which enables to achieve reliable DEM data of high accuracy with fewer acquisitions. For this goal, the use of an edited TanDEM$\mathrm{X}$ DEM as "starting point" for the processing is mandatory. Since the limited satellite resources and time do not allow several coverages for the majority of the landmass, the Change DEM is processed on the basis of the final TanDEM-X DEM product by a newly developed so-called "delta-phase" approach (Lachaise et al. 2016) instead of the Dual-Baseline-PhaseUnwrapping algorithm developed for the mission (Lachaise et al. 2018). This approach has been tested with demanding acquisition data of very low height-of-ambiguity, yielding a nearly error-free data set. It is important to note, that - although the process starts with the first global DEM - the new phase (height) values are independent of the old ones.

The absolute height accuracy which is driving the use for temporal height change detection will be in the same order as the first Global DEM, respectively well below 10 meters. The Change DEM will be generated as a 0.4 arcsec version, supplemented by a 1 arcsec and a 3 arcsec variant.

\section{CONCLUSION}

The acquisition of the global DEM being the primary goal of the TanDEM-X mission has been achieved in 2014. The data processing was completed in 2016. Further milestones were the generation of DEMs with increased horizontal and vertical resolution and the scientific exploitation of TanDEM-X in a dedicated mission phase that was not restricted by the constraints of the primary mission goal and therefore allowed a variety of different formation settings as well as special instrument and acquisition modes. Both satellites are still working very well and have plenty of resources left, which allows to continue the mission beyond 2020. The current focus is on the acquisition of an additional global coverage in order to generate a global Change DEM.

\section{REFERENCES}

Bojarski, A., Bachmann, M., Steinbrecher, U., Tous Ramon, N., Böer, J., Zink, M., 2018. TerraSAR-X and TanDEM- X System Status and System Response to Solar Related Events. In: Proceedings of the 12th European Conference on Synthetic Aperture Radar (EUSAR), pp. 1232 - 1236.

Buckreuss, S., Fritz, T., Bachmann, M., Zink, M., 2018. TerraSAR-X and TanDEM-X Mission Status. In: Proceedings of the 12th European Conference on Synthetic Aperture Radar (EUSAR), pp. 47-51. 
European Space Agency Climate Change Initiative (CCI), 2014. Global Water Bodies https://www.esa-landcovercci.org/?q=node/162 (6 August 2018).

Hajnsek, I., Busche, T., 2014. Announcement of Oppor-tunity: TanDEM-X Science Phase, public DLR Document TD-PD-PL0032 Issue $1.0 \mathrm{https} / / /$ tandemx-science.dlr.de/pdfs/TD-PDPL_0032TanDEM-X_Science_Phase.pdf (6 August 2018).

Krieger, G., Moreira, A., Fiedler, H., Hajnsek, I., Werner, M., Younis, M., Zink, M., 2007. TanDEM-X: A Satellite Formation for High Resolution SAR Interferometry. In: IEEE Transactions on Geoscience and Remote Sensing, Vol. 45, No. 11, pp. 33173341 .

Lachaise, M., Fritz, T., 2016. Update of the Interferometric Processing Algorithms for the TanDEM-X High Resolution DEMs. In: Proceedings of the 11th European Conference on Synthetic Aperture Radar (EUSAR), pp. 550-553.

Lachaise, M., Fritz, T., Bamler, R., 2018. The Dual-Baseline Phase Unwrapping Correction Framework for the TanDEM-X Mission Part 1: Theoretical Description and Algorithms. In: IEEE Trans. Geoscience and Remote Sensing, Vol. 56, Issue 2, pp. 780-798.

Ortega-Miguez, C., Schulze, D., Polimeni, M., Böer, J., Rizzoli, P., Bachmann, M., 2012. TanDEM-X Acquisition Planner. In: Proceedings of the 9th European Conference on Synthetic Aperture Radar (EUSAR), pp. 418-421.

Shimada, M., Itoh, T., Motooka, T., Watanabe, M., Shiraishi, T., Thapa, R., Lucas, R., 2014. New Global Forest/Non-Forest Maps from ALOS PALSAR Data (2007-2010). In: Remote Sensing of Environment, Vol. 155, pp. 13-31.

Wessel, B., 2016. TanDEM-X Ground Segment DEM Products Specification Document, public DLR Document TD-GS-PS-

0021 Issue $3.1 \mathrm{https}: / /$ tandemx-science.dlr.de/pdfs/TD-GS-PS 0021_DEM-Product-Specification_v3.1.pdf (6 August 2018). 